\title{
Analisis Postur Kerja Penjahit Nur Tailor Menggunakan Metode Rappid Entire Body Assessment
}

\author{
Ranti Haryani $^{(1)}$, Azmi $^{(2)}$, \\ Sirlyana ${ }^{(3)}$ \\ 1,2,3) Program Studi Teknik Industri, \\ Sekolah Tinggi Teknologi Dumai \\ Jl. Utama Karya Bukit Batrem II \\ Email: Ranty14haryani@gmail.com; \\ azmi.omy@gmail.com; \\ drasirlyana@gmail.com
}

\begin{abstract}
ABSTRAK
Penjahit Nur Tailor merupakan salah satu jasa penjahit yang ada di kota Dumai. Pekerjaan dengan posisi yang salah dan berulang-ulang dapat menyebabkan para penjahit sangat rentan untuk terkena gangguan MSDs, karena kurangnya pengetahuan dan pemahaman akan cara kerja yang baik dan benar. Tujuan penelitian dilakukan untuk mengetahui tingkat risiko cidera pada 2 orang penjahit pada saat menjahit atasan baju melayu laki-laki SMP 4 Dumai yang dilakukan oleh penjahit 1 dan menjahit atasan baju kotak-kotak laki-laki SMP 7 Purnama yang dilakukan oleh penjahit 2 dengan menggunakan kuesioner Nordic Body Map (NBM) untuk mengetahui cedera Musculoskeletal Disorders yang dialami pekerja, sedangkan untuk mengetahui tingkat risiko cedera pekerja menggunakan metode Rapid Entire Body Assessment (REBA). Hasil NBM yang paling berisiko cidera pada pekerja yaitu sakit pada leher atas dan bawah, bahu kiri dan kanan, batang tubuh, lengan atas kanan dan kiri, pinggang, bawah pinggang, pantat, lengan bawah kanan, pergelangan tangan kanan, paha kanan, lutut kanan, betis kanan, dan sakit pada kaki kanan. Tingkat resiko yang dialami penjahit Nur Tailor dengan menggunakan metode REBA pada saat menjahit baju melayu adalah sedang dengan level resiko 4-5 dan diperlukan tindakan dalam waktu dekat. Untuk tingkat resiko postur kerja pada saat menjahit kantong baju kotak-kotak adalah rendah dengan level risiko 3 dan dibutuhkan perbaikan postur kerja. Sedangkan tingkat risiko untuk postur melapisi kerah, menjahit badan, menjahit tangan dan menjahit kerah baju kotak-kotak adalah sedang dengan level risiko 4-5 dan diperlukan tindakan dalam waktu dekat. Kata kunci: Nordic Body Map, Penjahit, Rappid Entire Body Assessment
\end{abstract}

\begin{abstract}
Nur Tailor is one of the tailor services in Dumai city. Work with the wrong position and repeatedly can cause tailors to be very vulnerable to MSDs, due to lack of knowledge and understanding of how to work properly and correctly. The purpose of the study was to determine the level of risk of injury to 2 tailors when sewing male Malay tops at SMP 4 Dumai carried out by tailor 1 and sewing male plaid tops at SMP 7 Purnama conducted by tailor 2 using a questionnaire. Nordic Body Map (NBM) to find out Musculoskeletal Disorders injuries experienced by workers. To determine the level of risk of worker injury using the Rapid Entire Body Assessment (REBA) method. The results of the NBM that are most at risk of injury to workers are pain in the upper and lower neck, left and right shoulders, torso, right and left upper arms, waist, below the waist, buttocks, right forearm, right wrist, right thigh, right knee, right calf, and pain in the right leg. The level of risk experienced by Nur Tailor using the REBA method when sewing Malay clothes is moderate with a risk level of 4-5 and action is needed in the near future. For the level of risk of work posture when sewing plaid shirt pockets is low with a risk level
\end{abstract}


of 3 and it is necessary to improve work posture. While the risk level for the posture of lining the collar, sewing the body, sewing hands and sewing plaid shirt collar is moderate with a risk level of 4-5 and action is needed in the near future.

Keywords: Nordic Body Map, Tailor, Rappid Entire Body Assessment

\section{Pendahuluan}

Penjahit Nur Tailor merupakan salah satu jasa penjahit yang ada di kota Dumai. Produk yang ditawarkan berupa jasa yaitu jasa dalam membuat busana kerja wanita dan pria, seragam sekolah, dan lain sebagainya. Berdasarkan hasil kuesioner Nordic Body Map yang telah disebarkan didapati ada beberapa keluhan yang dirasakan oleh penjahit yang berjumlah 2 orang pada saat menjahit baju melayu laki-laki SMP 4 Dumai yang dilakukan oleh penjahit 1 dan menjahit baju kotak-kotak laki-laki SMP 7 Purnama yang dilakukan oleh penjahit 2. Persentase sakit pada leher atas adalah 50\%, leher bawah $100 \%$, bahu kiri $100 \%$, bahu kanan $100 \%$, lengan atas kiri $50 \%$, punggung $100 \%$, lengan atas kanan $100 \%$, pinggang $50 \%$, buttock $100 \%$, bottom $50 \%$, lengan bawah kanan 50\%, pergelangan tangan kanan 50\%, paha kanan 50\%, lutut kanan 100\%, betis kanan $100 \%$, kaki kanan $100 \%$.

Penelitian dilakukan untuk mengetahui tingkat risiko cedera pada pekerja, serta memberikan usulan perbaikan untuk mengurangi risiko cedera dengan menggunakan metode REBA (Rapid Entire Body Assessment). REBA adalah sebuah metode yang dikembangkan dalam bidang ergonomi yang menginvestigasi dan menilai posisi kerja yang dilakukan oleh tubuh bagian atas. Berdasarkan masalah yang telah ada, maka peneliti mengambil judul "Analisis Postur Kerja Penjahit Nur Tailor Menggunakan Metode Rapid Entire Body Assessment".

\section{Metode Penelitian}

Teknik pengumpulan data pada penelitian ini adalah data dari keluhan pekerja menggunakan kuesioner Nordic Body Map (Supriyanto, 2011) yang terdiri dari 2 bagian, yaitu bagian identitas pekerja dan bagian kuesioner. Sampel yang diambil sebanyak 2 orang penjahit Nur Tailor berdasarkan keluhan yang dirasakan. Penjahit 1 menjahit atasan baju melayu laki-laki SMP 4 Dumai dan penjahit 2 menjahit atasan baju kotak-kotak laki-laki SMP 7 Purnama. Data yang telah dikumpulkan dapat diolah dengan menggunakan metode REBA. Pada tahap awal pengambilan data, dilakukan dengan merekam kegiatan pekerja dan mengambil fotonya. Kemudian dilakukan pengolahan data dengan mengukur menggunakan busur derajat untuk mengetahui sudut pada postur tubuh pekerja. Setelah itu dilakukan perhitungan menggunakan metode REBA.

\section{Hasil danPembahasan}

Penjahit Nur Tailor melakukan lima gerakan postur tubuh yaitu, melapisi kerah, menjahit kantong, menjahit badan, menjahit tangan, menjahit kerah. Berikut gambar postur tubuh yang dilakukan oleh penjahit 1 pada saat menjahit atasan baju melayu lakilaki SMP 4 Dumai. 


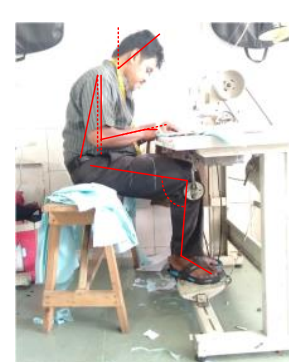

(a)

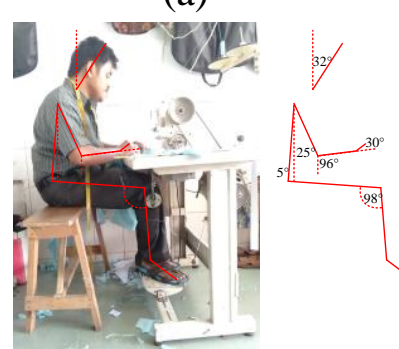

(d)
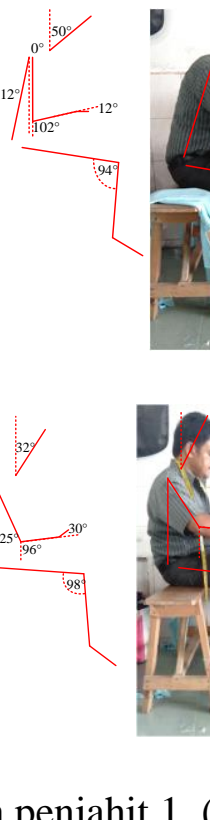

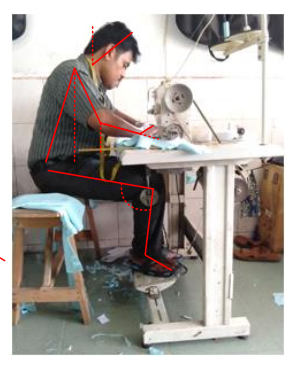

(b)
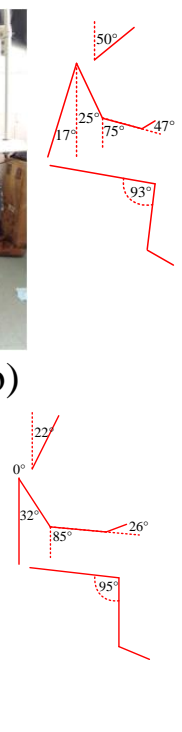

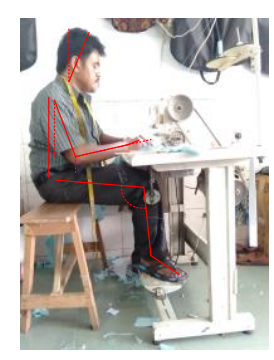

(c)

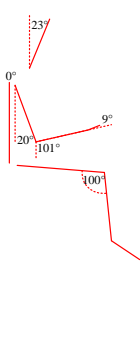

Gambar 1. Postur kerja penjahit 1, (a) melapisi kerah; (b) menjahit kantong; (c) menjahit badan; (d) menjahit tangan; (e) menjahit kerah

Gambar 1 merupakan skor REBA yang diperoleh untuk postur kerja penjahit 1 menjhait atasan baju melayu laki-laki SMP 4 Dumai saat melapisi kerah, menjahit kantong, menjahit badan, menjahit tangan, dan menjahit kerah. Penilaian skor A dapat dilihat pada Tabel 1 .

Tabel 1. Penilaian skor A penjahit saat melapisi kerah

\begin{tabular}{|c|c|c|c|c|c|c|c|c|c|c|c|c|c|}
\hline \multirow{4}{*}{ Tabel A } & \multicolumn{13}{|c|}{ Neck } \\
\hline & & \multicolumn{4}{|c|}{1} & \multicolumn{4}{|c|}{2} & \multicolumn{4}{|c|}{3} \\
\hline & \multirow{2}{*}{ Legs } & & & & & & & & & & & & \\
\hline & & 1 & 2 & 3 & 4 & 1 & 2 & 3 & 4 & 1 & 2 & 3 & 4 \\
\hline \multirow{5}{*}{$\begin{array}{l}\text { Trunk } \\
\text { postur } \\
\text { score }\end{array}$} & 1 & 1 & 2 & 3 & 4 & 1 & 2 & 3 & 4 & 3 & 3 & 5 & 6 \\
\hline & 2 & 2 & 3 & 4 & 5 & 3 & 4 & 5 & 6 & 4 & 5 & 6 & 7 \\
\hline & 3 & 2 & 4 & 5 & 6 & 4 & 5 & 6 & 7 & 5 & 6 & 7 & 8 \\
\hline & 4 & 3 & 5 & 6 & 7 & 5 & 6 & 7 & 8 & 6 & 7 & 8 & 9 \\
\hline & 5 & 4 & 6 & 7 & 8 & 6 & 7 & 8 & 9 & 7 & 8 & 9 & 9 \\
\hline
\end{tabular}

Sumber: Pengolahan Data, 2021

Tabel 1 merupakan penilaian skor A pada penjahit 1 melapisi kerah baju melayu. Hasil skor A yang didapat adalah 5 yang selanjutnya akan ditambahkan dengan skor beban yaitu 0, sehingga hasilnya 5. Perhitungan skor B dapat dilihat pada Tabel 2. 
Tabel 2. Penilaian skor B penjahit saat melapisi kerah

\begin{tabular}{|c|c|c|c|c|c|c|c|}
\hline \multirow{3}{*}{ Table B } & \multicolumn{7}{|c|}{ Lower Arm } \\
\cline { 2 - 8 } & & \multicolumn{7}{|c|}{1} & \multicolumn{3}{|c|}{2} \\
\cline { 2 - 8 } & \multirow{2}{*}{ Wrist } & \multicolumn{3}{|c|}{} & & \\
\cline { 2 - 8 } & 1 & 1 & 2 & 3 & 1 & 2 & 3 \\
\cline { 2 - 8 } & 2 & 1 & 2 & 3 & 2 & 3 & 4 \\
\cline { 2 - 8 } & 3 & 3 & 4 & 5 & 4 & 5 & 5 \\
\cline { 2 - 8 } Spper Arm & 4 & 4 & 5 & 5 & 5 & 6 & 7 \\
\cline { 2 - 8 } Score & 5 & 6 & 7 & 8 & 7 & 8 & 8 \\
\cline { 2 - 8 } & 6 & 7 & 8 & 8 & 8 & 9 & 9 \\
\hline
\end{tabular}

Sumber: Pengolahan Data, 2021

Tabel 2 merupakan penilaian skor B pada penjahit 1 melapisi kerah baju melayu. Hasil skor B yang didapat adalah 1 yang selanjutnya akan ditambahkan dengan skor coupling yaitu 0 , sehingga hasilnya 1 .

Tabel 3. Penilaian skor $\mathrm{C}$ penjahit saat melapisi kerah

\begin{tabular}{|c|c|c|c|c|c|c|c|c|c|c|c|c|}
\hline \multirow{3}{*}{ 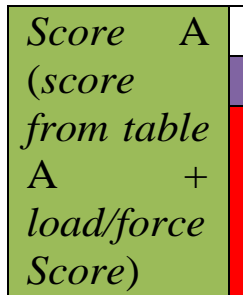 } & \multicolumn{12}{|c|}{ Table C } \\
\hline & \multicolumn{12}{|c|}{ Score B (table B value + coupling score) } \\
\hline & 1 & 2 & 3 & 4 & 5 & 6 & 7 & 8 & 9 & 10 & 11 & 12 \\
\hline 1 & 1 & 1 & 1 & 2 & 3 & 3 & 4 & 5 & 6 & 7 & 7 & 7 \\
\hline 2 & 1 & 2 & 2 & 3 & 4 & 4 & 5 & 6 & 6 & 7 & 7 & 8 \\
\hline 3 & 2 & 3 & 3 & 3 & 4 & 5 & 6 & 7 & 7 & 8 & 8 & 8 \\
\hline 4 & 3 & 4 & 4 & 4 & 5 & 6 & 7 & 8 & 8 & 9 & 9 & 9 \\
\hline 5 & 4 & 4 & 4 & 5 & 6 & 7 & 8 & 8 & 9 & 9 & 9 & 9 \\
\hline 6 & 6 & 6 & 6 & 7 & 8 & 8 & 9 & 9 & 10 & 10 & 10 & 10 \\
\hline 7 & 7 & 7 & 7 & 8 & 9 & 9 & 9 & 10 & 10 & 11 & 11 & 11 \\
\hline 8 & 8 & 8 & 8 & 9 & 10 & 10 & 10 & 10 & 10 & 11 & 11 & 11 \\
\hline 9 & 9 & 9 & 9 & 10 & 10 & 10 & 11 & 11 & 11 & 12 & 12 & 12 \\
\hline 10 & 10 & 10 & 10 & 11 & 11 & 11 & 11 & 12 & 12 & 12 & 12 & 12 \\
\hline 11 & 11 & 11 & 11 & 11 & 12 & 12 & 12 & 12 & 12 & 12 & 12 & 12 \\
\hline 12 & 12 & 12 & 12 & 12 & 12 & 12 & 12 & 12 & 12 & 12 & 12 & 12 \\
\hline
\end{tabular}

Sumber. Pengolahan Data, 2021

Tabel 3 merupakan penilaian skor $\mathrm{C}$ pada penjahit 1 melapisi kerah baju melayu. Hasil skor $\mathrm{C}$ yang didapat adalah 4 dan akan ditambahkan dengan skor aktivitas yaitu 1 . Hasil analisis postur kerja penjahit saat menjahit baju melayu secara keseluruhan dapat dilihat pada Tabel 4 berikut. 
Tabel 4. Hasil analisis tingkat risiko penjahit saat menjahit baju melayu

\begin{tabular}{|c|c|c|l|c|}
\hline No & $\begin{array}{c}\text { Tingkat } \\
\text { Risiko }\end{array}$ & $\begin{array}{c}\text { Jumlah } \\
\text { Pekerja }\end{array}$ & \multicolumn{1}{|c|}{ Postur } & \multirow{2}{*}{ Action } \\
\hline \multirow{3}{*}{1} & \multirow{3}{*}{ Sedang } & 1 & Melapisi kerah baju melayu & \multirow{2}{*}{ Diperlukan } \\
\cline { 3 - 4 } & 1 & Menjahit kantong baju melayu & \\
\cline { 3 - 4 } & 1 & Menjahit badan baju melayu & \\
\cline { 3 - 4 } & 1 & Menjahit kerah baju melayu & \\
\cline { 3 - 4 } & & 1 & & \\
& & & &
\end{tabular}

Sumber: Pengolahan Data, 2021

Berikut gambar postur tubuh yang dilakukan oleh penjahit 2 pada saat menjahit atasan baju kotak-kotak laki-laki SMP 7 Purnama.

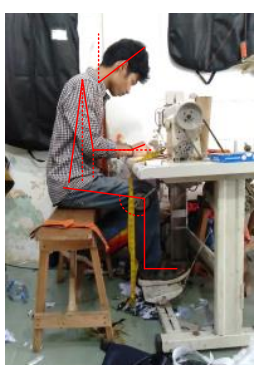

(a)

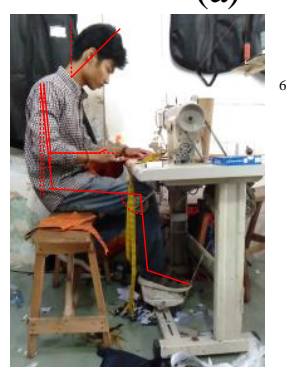

(d)

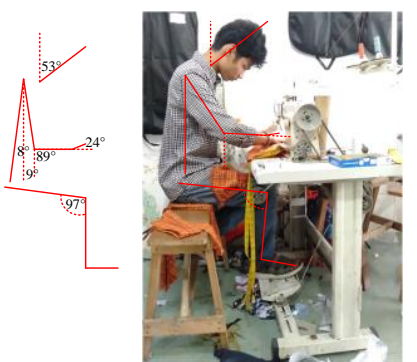

(b)
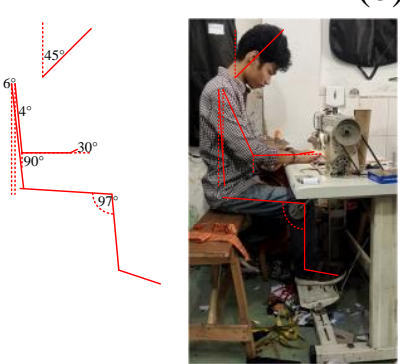

(e)

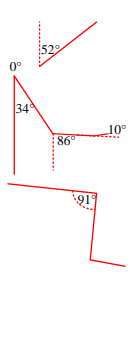

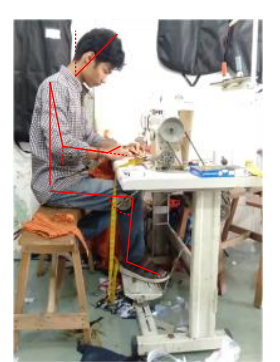

(c)

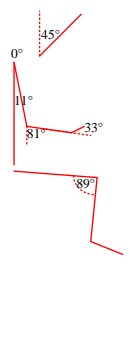

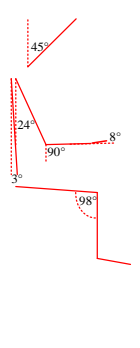

Gambar 2. Postur kerja penjahit 2, (a) melapisi kerah; (b) menjahit kantong; (c) menjahit badan; (d) menjahit tangan; (e) menjahit kerah

Gambar 2 merupakan skor REBA yang diperoleh untuk postur kerja penjahit 1 menjhait atasan baju Kotak-kotak laki-laki SMP 7 Purnama saat melapisi kerah, menjahit kantong, menjahit badan, menjahit tangan, dan menjahit kerah. 
Tabel 5. Penilaian skor A penjahit 2 melapisi kerah

\begin{tabular}{|c|c|c|c|c|c|c|c|c|c|c|c|c|c|}
\hline \multirow{4}{*}{ Tabel A } & \multicolumn{13}{|c|}{ Neck } \\
\hline & & \multicolumn{4}{|c|}{1} & \multicolumn{4}{|c|}{2} & \multicolumn{4}{|c|}{3} \\
\hline & \multirow{2}{*}{ Legs } & & & & & & & & & & & & \\
\hline & & 1 & 2 & 3 & 4 & 1 & 2 & 3 & 4 & 1 & 2 & 3 & 4 \\
\hline \multirow{5}{*}{$\begin{array}{l}\text { Trunk } \\
\text { postur } \\
\text { score }\end{array}$} & 1 & 1 & 2 & 3 & 4 & 1 & 2 & 3 & 4 & 3 & 3 & 5 & 6 \\
\hline & 2 & 2 & 3 & 4 & 5 & 3 & 4 & 5 & 6 & 4 & 5 & 6 & 7 \\
\hline & 3 & 2 & 4 & 5 & 6 & 4 & 5 & 6 & 7 & 5 & 6 & 7 & 8 \\
\hline & 4 & 3 & 5 & 6 & 7 & 5 & 6 & 7 & 8 & 6 & 7 & 8 & 9 \\
\hline & 5 & 4 & 6 & 7 & 8 & 6 & 7 & 8 & 9 & 7 & 8 & 9 & 9 \\
\hline
\end{tabular}

Sumber: Pengolahan Data, 2021

Tabel 5 merupakan penilaian skor A pada penjahit 2 melapisi kerah baju kotakkotak. Hasil skor A yang didapat adalah 5 yang selanjutnya akan ditambahkan dengan skor beban yaitu 0 , sehingga hasilnya 5 .

Tabel 6. Penilaian skor B penjahit 2 melapisi kerah

\begin{tabular}{|c|c|c|c|c|c|c|c|}
\hline \multirow{3}{*}{ Table $B$} & \multicolumn{7}{|c|}{ Lower Arm } \\
\cline { 2 - 8 } & & \multicolumn{7}{|c|}{1} & \multicolumn{3}{|c|}{2} \\
\cline { 2 - 8 } & \multirow{2}{*}{ Wrist } & \multicolumn{7}{|c|}{} & \multicolumn{3}{c|}{} \\
\cline { 2 - 8 } & 1 & 1 & 2 & 2 & 1 & 2 & 3 \\
\hline \multirow{5}{*}{$\begin{array}{c}\text { Upper Arm } \\
\text { Score }\end{array}$} & 2 & 1 & 2 & 3 & 2 & 3 & 4 \\
\cline { 2 - 8 } & 3 & 3 & 4 & 5 & 4 & 5 & 5 \\
\cline { 2 - 8 } & 4 & 4 & 5 & 5 & 5 & 6 & 7 \\
\cline { 2 - 8 } & 6 & 7 & 8 & 8 & 7 & 8 & 8 \\
\hline
\end{tabular}

Sumber: Pengolahan Data, 2021

Tabel 6 merupakan penilaian skor B pada penjahit 2 melapisi kerah baju kotakkotak. Hasil skor B yang didapat adalah 2 yang selanjutnya akan ditambahkan dengan skor coupling yaitu 0 , sehingga hasilnya 2 .

Tabel 7. Penilaian skor $\mathrm{C}$ penjahit 2 melapisi kerah

\begin{tabular}{|c|c|c|c|c|c|c|c|c|c|c|c|c|}
\hline \multirow{3}{*}{ 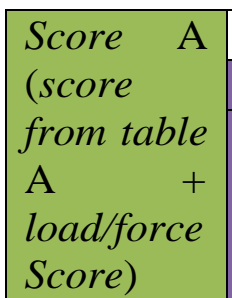 } & \multicolumn{12}{|c|}{ Table C } \\
\hline & \multicolumn{12}{|c|}{ Score B (table B value + coupling score) } \\
\hline & 1 & 2 & 3 & 4 & 5 & 6 & 7 & 8 & 9 & 10 & 11 & 12 \\
\hline 1 & 1 & 1 & 1 & 2 & 3 & 3 & 4 & 5 & 6 & 7 & 7 & 7 \\
\hline 2 & 1 & 2 & 2 & 3 & 4 & 4 & 5 & 6 & 6 & 7 & 7 & 8 \\
\hline 3 & 2 & 3 & 3 & 3 & 4 & 5 & 6 & 7 & 7 & 8 & 8 & 8 \\
\hline 4 & 3 & 4 & 4 & 4 & 5 & 6 & 7 & 8 & 8 & 9 & 9 & 9 \\
\hline 5 & 4 & 4 & 4 & 5 & 6 & 7 & 8 & 8 & 9 & 9 & 9 & 9 \\
\hline 6 & 6 & 6 & 6 & 7 & 8 & 8 & 9 & 9 & 10 & 10 & 10 & 10 \\
\hline 7 & 7 & 7 & 7 & 8 & 9 & 9 & 9 & 10 & 10 & 11 & 11 & 11 \\
\hline
\end{tabular}




\begin{tabular}{|c|c|c|c|c|c|c|c|c|c|c|c|c|}
\hline 8 & 8 & 8 & 8 & 9 & 10 & 10 & 10 & 10 & 10 & 11 & 11 & 11 \\
\hline 9 & 9 & 9 & 9 & 10 & 10 & 10 & 11 & 11 & 11 & 12 & 12 & 12 \\
\hline 10 & 10 & 10 & 10 & 11 & 11 & 11 & 11 & 12 & 12 & 12 & 12 & 12 \\
\hline 11 & 11 & 11 & 11 & 11 & 12 & 12 & 12 & 12 & 12 & 12 & 12 & 12 \\
\hline 12 & 12 & 12 & 12 & 12 & 12 & 12 & 12 & 12 & 12 & 12 & 12 & 12 \\
\hline
\end{tabular}

Sumber: Pengolahan Data, 2021

Tabel 7 merupakan penilaian skor $\mathrm{C}$ pada penjahit 2 melapisi kerah baju kotakkotak. Hasil skor $\mathrm{C}$ yang didapat adalah 4 dan akan ditambahkan dengan skor aktivitas yaitu 1. Hasil analisis postur kerja penjahit saat menjahit baju kotak-kotak secara keseluruhan dapat dilihat pada Tabel 8 berikut.

Tabel 8. Hasil analisis tingkat risiko pekerjaan menjahit baju kotak-kotak

\begin{tabular}{|c|c|c|c|c|}
\hline No & $\begin{array}{c}\text { Tingkat } \\
\text { Risiko }\end{array}$ & $\begin{array}{c}\text { Jumlah } \\
\text { Pekerja }\end{array}$ & \multicolumn{1}{|c|}{ Postur } & Action \\
\hline 1 & Rendah & 1 & Menjahit kantong baju kotak-kotak & Mungkin perlu \\
\hline \multirow{2}{*}{2} & \multirow{2}{*}{ Sedang } & 1 & Melapisi kerah baju kotak-kotak & \\
\cline { 3 - 4 } & & 1 & Menjahit badan baju kotak-kotak & \multirow{2}{*}{ Diperlukan } \\
\cline { 3 - 4 } & & 1 & Menjahit tangan baju kotak-kotak & \\
\cline { 3 - 4 } & & & & \\
\hline
\end{tabular}

Sumber: Pengolahan Data, 2021

\section{Kesimpulan}

Kesimpulan yang didapat untuk tingkat resiko yang dialami penjahit Nur Tailor dengan menggunakan metode REBA pada saat menjahit baju melayu adalah sedang dengan level resiko 4-5 dan diperlukan tindakan dalam waktu dekat. Untuk tingkat resiko postur kerja pada saat menjahit kantong baju kotak-kotak adalah rendah dengan level risiko 3 dan dibutuhkan perbaikan postur kerja. Sedangkan tingkat risiko untuk postur melapisi kerah, menjahit badan, menjahit tangan dan menjahit kerah baju kotak-kotak adalah sedang dengan level risiko 4-5 dan diperlukan tindakan dalam waktu dekat. Pada saat menjahit postur kaki tidak mengalami perubahan.

\section{Daftar Pustaka}

Andriani, M., 2017, Identifikasi Postur Kerja Secara Ergonomi untuk Menghindari Musculoskeletal Disorders, Jurnal Teknik Industri, ISSN: 2338-7122.

Astari, A., 2017, Gambaran Postur Kerja Petani Rumput Laut dengan Metode REBA di Pulau Kanalo Dua Kec. Pulau Sembilan Kab. Sinjai, Skripsi, Sarjana Kesehatan Masyarakat, UIN Alauddin, Makasar.

Azmi, Fitra, dan Suroso, M., (2021), Penerapan Data Antropometri Dalam Perancangan Alat Pengupas Sabut Kelapa Ekonomis, Jurnal ARTI (Aplikasi Rancangan Teknik Industri), VOL.16 NO 1 (2021) Desember 2020 - Mei 2021, Hal: 94-99 
Iridiastadi, H., dan Yassierli, 2014, Ergonomi Suatu Pengantar, PT Remaja Rosdakarya, Bandung.

Kurnia, F., dan Sobirin, M., 2020, Analisis Tingkat Kualitas Postur Pengemudi Becak Menggunakan Metode RULA dan REBA, Jurnal Engine Energi, Manufactur dan Material, Vol. 4, No. 1, ISSN: 2579-7433.

Rahman, A., 2017, Analisis Postur Kerja dan Faktor yang Berhubungan dengan Keluhan Musculoskeletal Disorders (Msds) pada Pekerja Beton Sektor Informal di Kelurahan Samata Kecamatan Somba Opu Kabupaten Gowa, Skripsi, Sarjana Kesehatan Masyarakat, UIN Alauddin Makassar.

Restuputri, D.P., Lukman, M., dan Wibowo, 2017, Metode REBA untuk Pencegahan Musculoskeletal Disorder Tenaga Kerja, Jurnal Teknik Industry, Vol. 18, No. 01, ISSN 1978-1431.

Sutalaksana, I.Z., Anggawisastra, R., dan Tjakraatmadja, J.H., 2006, Teknik Perancangan Sistem Kerja, ITB, Bandung.Setiorini, A., Musyarofah, S., Mushidah, dan Widjasena, B., 2019, Analisis Postur Kerja dengan Metode REBA dan Gambaran Keluhan Subjektif Musculoskeletal Disorders MSDs pada Pekerja Sentra Industri Tas Kendal Tahun 2017, Jurnal Kesehatan, ISSN 26207761.

Supriyanto, 2011, Perancangan Postur Kerja pada Pekerja Bagian Pencucian dan Penggilingan Kedelai dengan Pendekatan REBA untuk Mengurangi Risiko MSDs, Skripsi, Teknik Industri, Universitas Sebelas Maret, Surakarta.

Yulistyari, E.I., dan Setianah, P., 2018, Analisis Perbaikan Postur Kerja dengan Pendekatan Ergonomi pada Home Industry JKS Snack \& Catering di SerangBanten, Journal Industrial Manufacturing, Vol. 3, No. 1, ISSN: 2502-4582. 